\title{
DESEMPENHO DE SEMENTES NUAS E PELETIZADAS DE ALFACE (Lactuca sativa L.) SUBMETIDAS A ESTRESSES HÍDRICO E TÉRMICO ${ }^{1}$
}

\author{
CARLA MEDIANEIRA BERTAGNOLLI², NILSON LEMOS DE MENEZES ${ }^{3}$, LINDOLFO STORCK ${ }^{4}$, \\ OSMAR SOUZA DOS SANTOS ${ }^{4}$, LEANDRO LOURENÇO PASQUALLI ${ }^{5}$
}

\begin{abstract}
RESUMO - A alface é a hortaliça folhosa de maior importância na alimentação dos brasileiros. Seu plantio é feito por meio de sementes, cujo tamanho reduzido dificulta o seu manuseio. Além disto, essas sementes apresentam dificuldades na germinação quando submetidas a condições desfavoráveis de umidade e temperatura. O presente trabalho teve como objetivo estudar o desempenho fisiológico de sementes nuas e peletizadas de alface da cv. Karla sob diferentes potenciais hídricos e temperaturas. As sementes foram colocadas para germinar sobre papel filtro umedecido com solução de polietileno glicol (PEG 6000), nos níveis de zero, -0,3; -0,6; e -0,9MPa, associados às temperaturas de $20,25,30$ e $35^{\circ} \mathrm{C}$. A qualidade fisiológica das sementes foi avaliada por meio do teste de germinação, primeira contagem e índice de velocidade de germinação. Concluiu-se que para potenciais hídricos menores ou iguais a -0,3MPa e nas temperaturas iguais ou superiores a $25^{\circ} \mathrm{C}$ ocorreu redução na velocidade e porcentagem de germinação de sementes de alface da cv. Karla. O potencial hídrico de -0,9MPa e/ou a temperatura de $35^{\circ} \mathrm{C}$ impediram a germinação das sementes nuas e peletizadas. As sementes nuas tiveram maior redução na qualidade fisiológica do que as sementes peletizadas, quando submetidas a condições de estresses hídrico e térmico.
\end{abstract}

Termos para indexação: germinação, potencial hídrico, temperatura, qualidade fisiológica.

\section{PERFORMANCE OF BARE AND PELLETED LETTUCE (Lactuca sativa L.) SEEDS EXPOSED TO HYDRIC AND THERMAL STRESSES}

\begin{abstract}
Lettuce is the most important leafy vegetable in Brazil. Its planting is made by seeds, which are small, making their handling difficult. Moreover lettuce seeds present low germination when submitted to unfavorable moisture and temperature conditions. The objective of this work was to study the physiological performance of bare and pelleted lettuce seeds, cv. Karla, under different hydric and temperature potentials. Both kinds of seeds were placed to germinate on filter paper wetted with solutions of polyethylene glycol (PEG 6000), with the following levels of water potential: zero, $-0.3,-0.6$ and $-0.9 \mathrm{MPa}$. Seeds from each water potential treatment were placed to germinate under four temperatures: $20,25,30$ and $35^{\circ} \mathrm{C}$. The physiological quality of the seeds was evaluated by germination test, first counting and speed of germination index. It was concluded that water potentials lower than or equal to - $0.3 \mathrm{MPa}$, and temperatures equal to or greater than $25^{\circ} \mathrm{C}$ caused a reduction in the speed and percentage of germination of lettuce seeds. The water potential of $-0.9 \mathrm{MPa}$ and/or the temperature of $35^{\circ} \mathrm{C}$ inhibited seed germination of bare and pelleted seeds. Bare seeds had larger reduction in physiological quality than pelleted seeds when exposed to hydric and thermal stress.

Index terms: germination, water potential, temperature, physiological quality.
\end{abstract}

${ }^{1}$ Aceito para publicação em 08.01.2003.

${ }^{2}$ Eng $^{\mathrm{a}}$ Agra ${ }^{\mathrm{a}}$, MSc, Doutoranda do Curso de Pós-Graduação em Ciência e Tecnologia de Sementes, FAEM/UFPel, Pelotas, RS.

${ }^{3}$ Eng $^{\circ}$ Agr $^{\circ}$, Prof. Adjunto, Depto. de Fitotecnia, Centro de Ciências Rurais,
UFSM, 97105-900, Santa Maria, RS; e-mail: nmenezes@ccr.ufsm.br

${ }^{4}$ Eng $^{\text {O }}$ Agro $^{\circ}$, Prof. Titular, Depto. de Fitotecnia, Centro de Ciências Rurais, UFSM.

${ }^{5}$ Acadêmico do Curso de Agronomia, UFSM. 


\section{INTRODUÇÃO}

A alface (Lactuca sativa L.) é a hortaliça folhosa mais importante na alimentação dos brasileiros. Seu plantio é feito por meio de sementes, as quais apresentam particular sensibilidade às variações na umidade e temperatura do meio onde germinam, podendo ser afetadas em germinação e vigor. Além disso, devido ao seu tamanho reduzido, a operação de semeadura apresenta dificuldades.Tal fato tem estimulado o uso dos mais variados tratamentos nas sementes, entre os quais a peletização, que vem sendo muito utilizada. Esta consiste na aplicação de materiais sólidos, em quantidade suficiente para a formação de grânulos (Sampaio \& Sampaio, 1994), que facilitam o manuseio na semeadura e a produção de mudas em bandejas.

Os fatores externos (ambientais) que têm influência direta sobre a germinação das sementes são o oxigênio, temperatura e a água. A temperatura afeta a germinação total, a velocidade de germinação, a velocidade de absorção de água e as reações bioquímicas, que determinam todo o processo germinativo (Carvalho \& Nakagawa, 1988).

As sementes de alface podem sofrer termo-inibição quando embebidas a temperaturas acima de $30^{\circ} \mathrm{C}$. A inibição momentânea pode ser eliminada e elas podem voltar a germinar após retornarem à temperatura adequada (Kaufmann \& Roos, 1970; Guedes \& Cantliffe, 1980; Pill \& Rojas, 1987 e Coons et al., 1990).

A termo-dormência, que é um efeito mais drástico das temperaturas elevadas, segundo Valdes \& Bradford (1987), pode ser agravada pelo uso de sementes peletizadas. De acordo com Nascimento \& Caliari (1989), sementes peletizadas de alface mostraram-se mais sensíveis a altas temperaturas.

A água é o fator que exerce a mais determinante influência sobre o processo de germinação. Da absorção de água, resulta a reidratação dos tecidos, com a conseqüente intensificação da respiração e de todas as outras atividades metabólicas, que culminam com o fornecimento de energia e nutrientes necessários para a retomada de crescimento do eixo embrionário (Carvalho \& Nakagawa, 1988).

As sementes peletizadas, devido às diferentes características hidrofílicas e hidrofóbicas dos materiais utilizados no recobrimento, podem apresentar um comportamento diferente quando submetidas a distintos potenciais hídricos e/ou temperaturas, quando comparadas com as sementes nuas.

Potenciais hídricos muito negativos, especialmente no início da embebição, influenciam a absorção de água e podem inviabilizar a seqüência de eventos que culminam com a emergência das plântulas (Bansal et al., 1980), retardando ou reduzindo a velocidade de germinação em muitas espécies vegetais por interferir na hidratação da semente (Prisco \& O’Leary citados por Tambelini \& Perez, 1998).

Sabe-se pouco sobre o efeito do estresse hídrico em diferentes temperaturas. Segundo Kaufmann \& Roos (1970), a temperatura afeta a relação entre o potencial hídrico e a germinação das sementes de alface var. Mesa 659. Eles verificaram que, na temperatura de $15^{\circ} \mathrm{C}$, não ocorreu germinação no potencial hídrico de - 0,8Mpa, sendo que na temperatura de $25^{\circ} \mathrm{C}$, houve uma drástica queda na germinação a - 0,4MPa; porém, na temperatura de $35^{\circ} \mathrm{C}$, não ocorreu germinação das sementes, mesmo no potencial nulo. Resultados semelhantes obtiveram Coons et al. (1990) em dez cultivares de alface, visto que a $20^{\circ} \mathrm{C}$ e $25^{\circ} \mathrm{C}$ apresentaram $100 \%$ de germinação quando submetidas a potenciais de até - 0,9Mpa. Por outro lado, a $30^{\circ} \mathrm{C}$, houve um decréscimo significativo na germinação a - 0,6MPa; a $35^{\circ} \mathrm{C}$ ocorreu apenas $6 \%$ de germinação.

As sementes de alface apresentam então alta sensibilidade às condições do ambiente. Em situações agrícolas, a disponibilidade de água é mais problemática nas altas do que nas baixas temperaturas (Kaufmann \& Roos, 1970). Tais fatos são responsáveis pelo atraso na emergência de plântulas e, posteriormente, pela má qualidade na produção de mudas.

Considerando a hipótese de que os estresses hídrico e térmico afetam de modo distinto o potencial fisiológico de sementes nuas e peletizadas de alface, inclusive no sistema de cultivo hidropônico, estabeleceu-se como objetivos nesse trabalho estudar o desempenho de sementes nuas e peletizadas de alface da cv. Karla, sob diferentes potenciais hídricos e temperaturas.

\section{MATERIAL E MÉTODOS}

Foram utilizadas sementes peletizadas e sementes nuas de alface da cultivar Karla que, após removidas da embalagem hermética, foram mantidas em câmara seca, sob as condições de $10^{\circ} \mathrm{C}$ e $45 \%$ de umidade relativa do ar. As sementes nuas e peletizadas pertenciam ao mesmo lote inicial, sendo que para a obtenção das sementes nuas foi retirado o "pellet".

Os tratamentos constituíram-se dos níveis dos fatores solução osmótica, temperatura e sementes nuas e peletizadas. Utilizaram-se quatro níveis de solução osmótica, obtidas com o uso de Polietileno glicol 6000 (PEG 6000), nas quantidades indicadas por Villela et al. (1991), para estabelecer os potenciais osmóticos de zero, - $0,3,-0,6$ e -0,9MPa. Os quatro 
níveis do fator temperatura foram 20,25 , 30 e $35^{\circ} \mathrm{C}$, estabelecidos em germinador para as avaliações que foram realizadas por meio dos testes de: germinação, primeira contagem de germinação e índice de velocidade de germinação (IVG).

O teste de germinação foi conduzido em caixas plásticas do tipo gerbox, com quatro repetições de 100 sementes, colocadas sobre papel filtro umedecido com as soluções osmóticas nos potenciais mencionados e com água destilada para o potencial zero. Em seguida, as caixas plásticas foram mantidas em germinadores regulados às temperaturas citadas, por um período de sete dias. As contagens e a interpretação foram realizadas segundo Brasil (1992).

A primeira contagem foi determinada juntamente com o teste de germinação, computando-se as plântulas normais no quarto dia após a instalação do teste.

O Índice de Velocidade de Germinação (IVG) foi realizado utilizando-se a mesma metodologia de instalação do teste de germinação. As contagens diárias foram realizadas sempre no mesmo horário, a partir do aparecimento da primeira plântula normal igual ou maior que $1,5 \mathrm{~cm}$ e prosseguiu até o surgimento da última plântula normal. Com os dados coletados diariamente determinou-se o IVG, empregando-se a fórmula proposta por Maguire (1962).

Os dados foram analisados segundo o delineamento inteiramente casualizado, com esquema fatorial (4 potenciais osmóticos x 4 temperaturas x 2 tipos de sementes), com quatro repetições. Foram realizados a análise da variância e o estudo da regressão para os potenciais osmóticos e temperaturas, sendo que, para os testes de hipóteses das variáveis, germinação e primeira contagem, procedeu-se à transformação arco seno.

\section{RESULTADOS E DISCUSSÃO}

Observa-se, na Figura 1, a porcentagem de germinação das sementes nuas e peletizadas de alface da cv. Karla submetidas aos estresses hídrico e térmico, onde houve decréscimos na germinação com aumento da temperatura e com redução nos potenciais hídricos, sendo que as sementes peletizadas se mostraram mais tolerantes aos estresses hídrico e térmico.

As sementes de alface sob temperatura de $20^{\circ} \mathrm{C}$ apresentaram porcentagem de germinação entre 99 e 87\% quan-
Temperatura $20^{\circ} \mathrm{C}$

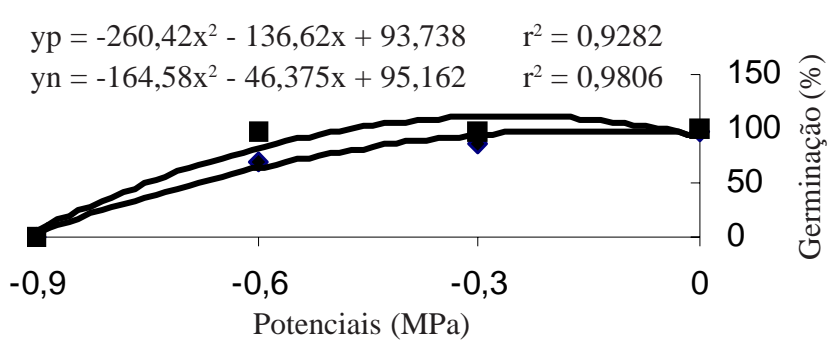

Temperatura $25^{\circ} \mathrm{C}$

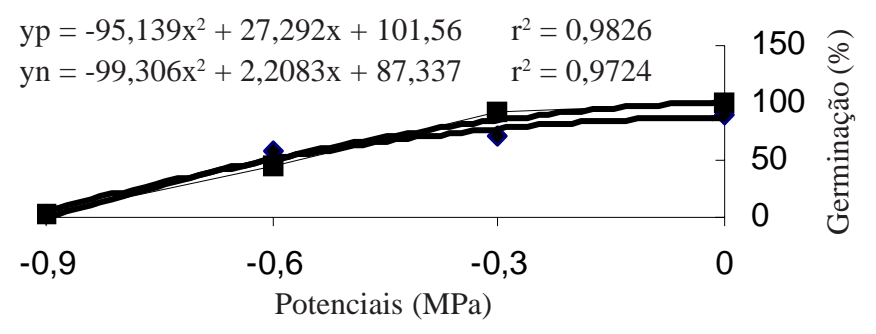

Temperatura $30^{\circ} \mathrm{C}$

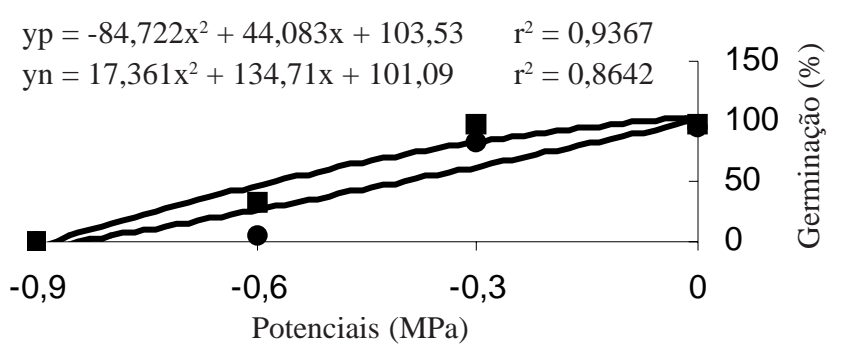

Temperatura $35^{\circ} \mathrm{C}$

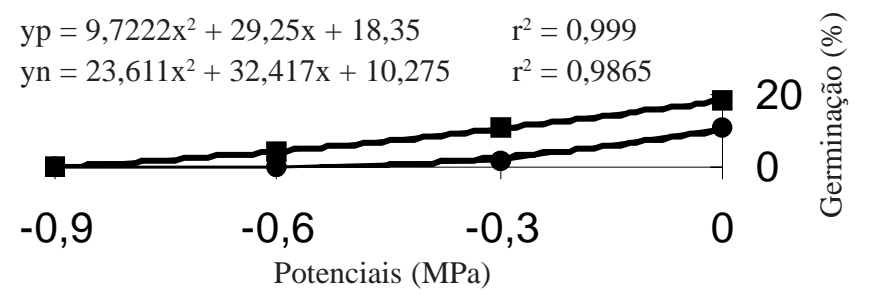

- Sementes nuas $\rightarrow$ - Sementes peletizadas

FIG. 1. Percentagens de germinação de sementes nuas (yn) e sementes peletizadas (yp) de alface da cv. Karla submetidas a estresses hídrico e térmico. 
do submetidas a potenciais hídricos de zero até -0,3MPa, demonstrando que as sementes nuas e peletizadas apresentavam boa qualidade fisiológica. Estes resultados são semelhantes àqueles obtidos por Kaufmann \& Roos (1970) onde sementes de alface cv. Mesa 659, de boa qualidade, mantiveram boa germinação quando expostas à temperatura de $20^{\circ} \mathrm{C}$ e potenciais de $-0,4 \mathrm{MPa}$.

A partir do potencial -0,3Mpa para sementes nuas e -0,6MPa para sementes peletizadas, houve redução no percentual germinativo, que se tornou mais acentuada a medida em que diminuiu o potencial hídrico, chegando a valores próximos de zero quando as sementes foram colocadas em substratos umedecidos com soluções osmóticas de potencial -0,9MPa, demonstrando que neste potencial o estresse hídrico já é totalmente limitante ao processo de germinação. Potenciais hídricos muito negativos no início da embebição interferem na absorção de água podendo dificultar a seqüência de eventos que culminam com a emissão da raiz primária.

Na temperatura de $25^{\circ} \mathrm{C}$, o comportamento germinativo foi semelhante ao da temperatura de $20^{\circ} \mathrm{C}$, pois houve decréscimo na germinação com a redução do potencial hídrico. Kaufmann \& Roos (1970) também verificaram queda na germinação quando utilizaram temperatura a partir de $25^{\circ} \mathrm{C}$ e potencial de -0,4 MPa.

A temperatura de $30^{\circ} \mathrm{C}$, no potencial hídrico de zero MPa, não reduziu a germinação das sementes, indicando boa adaptação da cultivar a temperaturas elevadas. Esse desempenho também deve estar associado à boa qualidade das sementes, pois essas apresentam melhor germinação em altas temperaturas, como observaram Nascimento \& Cantliffe (1999). No entanto, a redução do potencial hídrico nesta temperatura diminuiu drasticamente a germinação, como haviam observado Coons et al. (1990).

A temperatura de $35^{\circ} \mathrm{C}$ foi a mais prejudicial à germinação das sementes, pois mesmo a zero MPa, a máxima germinação foi de $20 \%$. Nesta temperatura, quando se reduziram os potenciais hídricos, a germinação tornou-se insignificante e, antes de chegar ao potencial de -0,6MPa, tornou-se nula. Esses resultados estão de acordo com aqueles obtidos por diversos autores (Kaufmann \& Roos, 1970; Coons et al., 1990; Nascimento \& Cantliffe, 1999 e Menezes et al., 2000) onde as temperaturas superiores a $30^{\circ} \mathrm{C}$ e, principalmente, a de $35^{\circ} \mathrm{C}$ levam à termo-inibição ou termodormência em sementes de alface, que associadas aos potenciais negativos inviabilizam a germinação.

Segundo Valdes \& Bradford (1987), o problema da termodormência pode ser agravado em sementes peletizadas, porém tal fato não foi verificado no presente estudo, provavelmente, devido à natureza do material usado na peletização e às características da cultivar.

Quando se comparou o desempenho das sementes nuas com o das peletizadas, as nuas mostraram-se mais sensíveis ao estresse hídrico na temperatura de $20^{\circ} \mathrm{C}$ (Figura 1). Quando expostas a $25^{\circ} \mathrm{C}$, a diferença de germinação entre as sementes nuas e as peletizadas diminuiu. Nas temperaturas de $30^{\circ} \mathrm{C}$ e $35^{\circ} \mathrm{C}$, as diferenças entre sementes nuas e peletizadas foram maiores. Estas diferenças, possivelmente, se devem à composição do material utilizado no recobrimento das sementes, pois estas se comportam diferentemente quando submetidas a diferentes potenciais hídricos e temperaturas.

De modo distinto ao observado neste experimento, Valdes \& Bradford (1987) verificaram que a $20^{\circ} \mathrm{C}$ não houve diferenças significativas entre as sementes nuas e peletizadas, quanto à germinação. Porém a $35^{\circ} \mathrm{C}$, as sementes peletizadas mostraram maior sensibilidade a essa alta temperatura. Após cinco meses, as sementes foram testadas novamente e a diferença no desempenho entre sementes nuas e peletizadas diminuiu. Também, há discordância entre os resultados aqui discutidos e aqueles obtidos por Nascimento \& Caliari (1989), que verificaram que sementes peletizadas da cultivar Floresta foram mais sensíveis a altas temperaturas. Da mesma forma, Macchia citado por Sampaio \& Sampaio (1994) relata que a temperatura ótima para a germinação de sementes de cebola e alface foi menor para sementes peletizadas do que para as nuas.

Essas variações se tornam possíveis devido às diferenças entre os experimentos, com modificações entre cultivares, tratamentos e condições de realização.

A elevação da temperatura e a diminuição do potencial hídrico influenciam na absorção de água pela semente e esta, por sua vez, afeta a emissão da raiz primária. Tal efeito pode ser modificado pelas características hidrofílicas ou hidro-fóbicas dos materiais utilizados para peletização das sementes, como observaram Robinson (1976) e Silva \& Nakagawa (1998a e 1998b). Assim, as diferenças entre os resultados, aqui verificados, são reflexos dos muitos fatores envolvidos.

Os dados de primeira contagem estão apresentados na Figura 2. Observa-se que os estresses reduziram a porcentagem de plântulas normais aos quatro dias após o início do teste de germinação.

Na temperatura de $20^{\circ} \mathrm{C}$, verificou-se que, para os dois tipos de sementes, houve redução na formação de plântulas com o decréscimo dos potenciais hídricos, o que influencia a 
Temperatura $20^{\circ} \mathrm{C}$

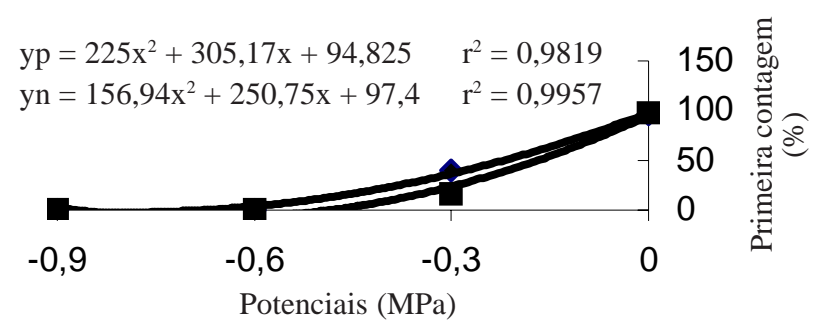

Temperatura $25^{\circ} \mathrm{C}$

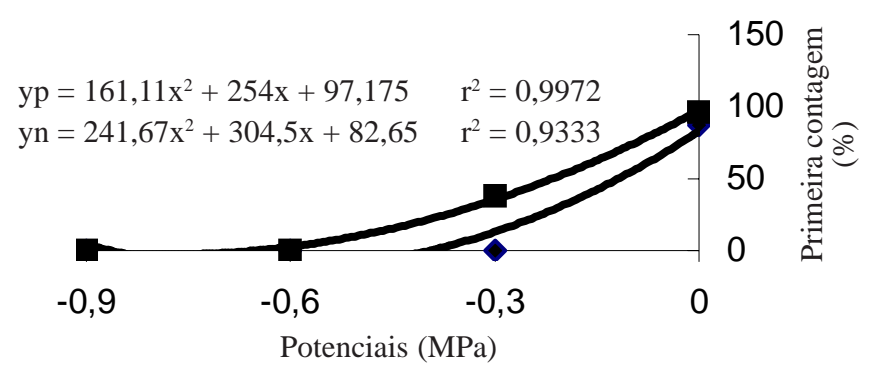

Temperatura $30^{\circ} \mathrm{C}$

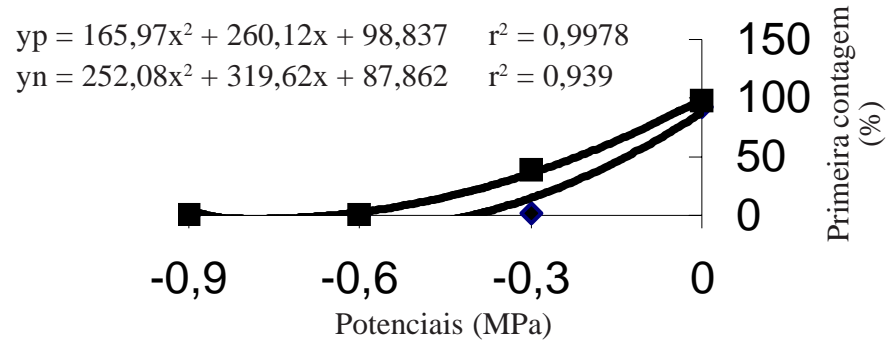

Sementes nuas $\mathbf{a}$ Sementes peletizadas

FIG. 2. Primeira contagem do teste de germinação de sementes nuas (yn) e sementes peletizadas (yp) de alface da cv. Karla submetidas a estresses hídrico e térmico.

absorção de água (Bansal et al., 1980), reduz a velocidade ou impede a emissão da raiz primária (Lopes et al., 1996). Nessa temperatura favorável para a germinação $\left(20^{\circ} \mathrm{C}\right)$, as sementes nuas apresentaram maior porcentagem de plântulas normais. As sementes peletizadas demoraram mais para embeber e desenvolver seus processos germinativos; no entanto esse atraso na formação das plântulas não foi considerado como baixo vigor das sementes, mas sim como dificuldades causadas pela peletização, conforme Roos \& Jackson (1976).
As temperaturas de $25^{\circ} \mathrm{C}$ e $30^{\circ} \mathrm{C}$ também tiveram efeito significativo na primeira contagem do teste de germinação, pois houve redução na porcentagem de plântulas normais, que se acentuou a partir do potencial de -0,3MPa, sendo que, já no potencial de -0,6 não houve a formação de plântulas normais. As sementes nuas sofreram efeitos negativos mais intensos do que as peletizadas, que mostraram maior porcentagem de plântulas normais. Isto ocorreu, provavelmente, devido às características do material da peletização, o qual ajudou a manter o desempenho das sementes, à medida que a temperatura se afastava da mais adequada.

$\mathrm{Na}$ temperatura de $35^{\circ} \mathrm{C}$ não houve a formação de plântulas normais até o quarto dia após o início do teste de germinação, o que concorda com vários autores, entre eles Kaufmann \& Roos (1970), Valdes \& Bradford (1987), Coons et al. (1990) e Menezes et al. (2000).

Na Figura 3 são apresentados os resultados relativos ao IVG das sementes. Nas temperaturas de $20^{\circ} \mathrm{C}, 25^{\circ} \mathrm{C}$ e $30^{\circ} \mathrm{C}$, as sementes nuas e peletizadas apresentaram uma redução no IVG, à medida em que diminuiu a disponibilidade hídrica.

Potenciais de -0,3 e -0,6MPa reduziram drasticamente a velocidade de germinação das sementes, conforme também observado por Prisco \& O’Leary, citados por Tambelini \& Perez (1998).

O potencial de -0,9MPa impediu a germinação e a manifestação do vigor das sementes, tanto no teste de primeira contagem como no IVG, em todas as temperaturas. Nas temperaturas estudadas, as sementes peletizadas apresentaram maior IVG do que as nuas. Na temperatura de $20^{\circ} \mathrm{C}$, esses resultados são contrários àqueles verificados na primeira contagem de germinação, pois o período de germinação foi mais longo para as sementes nuas, fato que influiu diretamente no índice.

A partir da temperatura de $25^{\circ} \mathrm{C}$, o comportamento das sementes peletizadas foi superior ao das nuas, como havia sido observado no teste de primeira contagem da germinação. O tratamento de peletização não prejudicou a qualidade das sementes e ainda favoreceu o desempenho nas condições adversas impostas às sementes.

$\mathrm{Na}$ temperatura de $35^{\circ} \mathrm{C}$ os índices de velocidade de germinação, embora tenham tido o mesmo comportamento que nas demais temperaturas, alcançaram valores muito baixos. As sementes apresentaram alta sensibilidade às condições do ambiente, como haviam enfatizado Kaufmann \& Roos (1970), quando afirmaram que a disponibilidade de água é mais problemática em altas temperaturas. 
Temperatura $20^{\circ} \mathrm{C}$

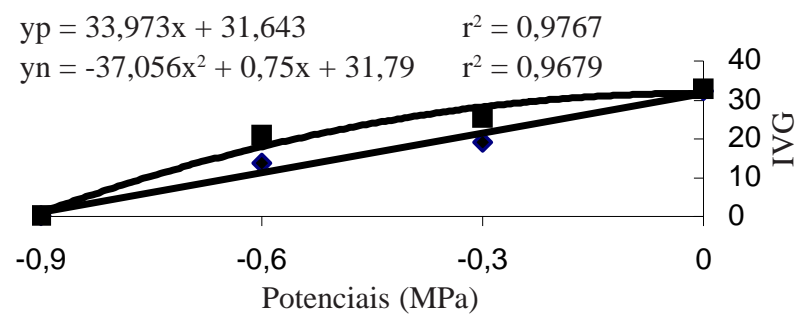

Temperatura $30^{\circ} \mathrm{C}$

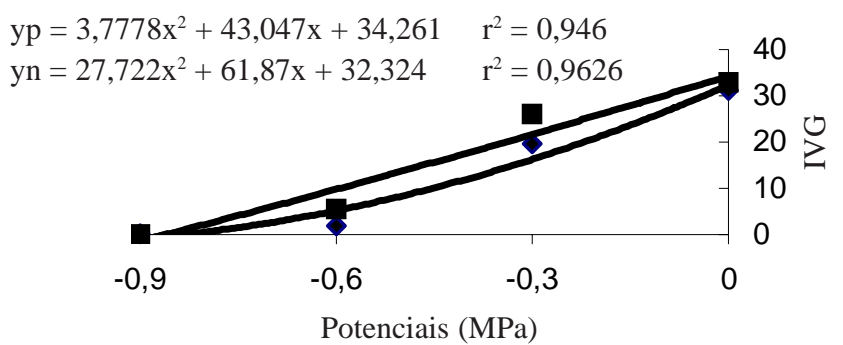

Temperatura $25^{\circ} \mathrm{C}$

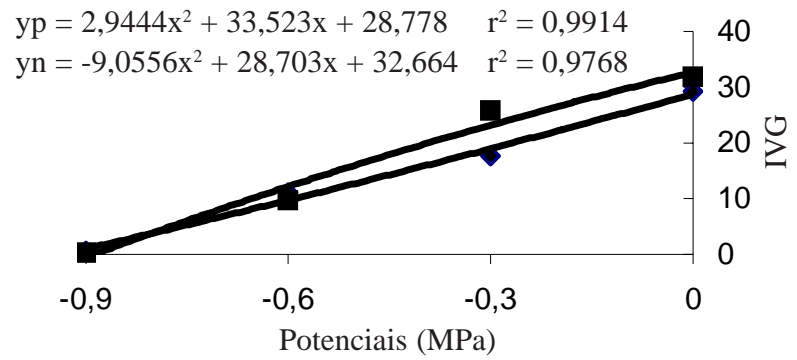

Temperatura $35^{\circ} \mathrm{C}$

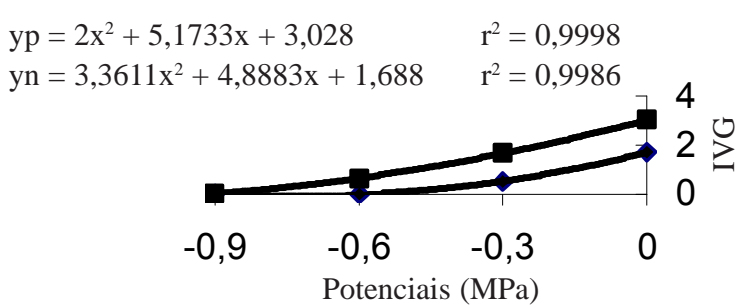

Sementes nuas

Sementes peletizadas

FIG. 3. Índice de velocidade de germinação de sementes nuas (yn) e peletizadas (yp) de alface da cv. Karla submetidas a estresses hídrico e térmico.

\section{CONCLUSÕES}

- Considerando-se os potenciais estudados, a redução da germinação das sementes de alface da cv. Karla ocorreu a partir do potencial hídrico de -0,3 MPa, nas temperaturas igual ou superiores a $25^{\circ} \mathrm{C}$.

- A temperatura de $35^{\circ} \mathrm{C}$ e/ou potencial hídrico de -0,9MPa impediram a germinação das sementes nuas e peletizadas.

- As sementes nuas submetidas a estresses hídrico e térmico tiveram maior redução da qualidade fisiológica do que as peletizadas.

\section{REFERÊNCIAS}

BANSAL, R.P.; BHATI, P.R.; SEM, D.N. Differential specificity in water inhibition of Indian arid zone. Biologia Plantarum, Praha, v.22, n.2, p.327-331, 1980.

BRASIL. Ministério da Agricultura e da Reforma Agrária/SNDA. Regras para análise de sementes. Brasília: SNDA/DNDV/CLAV, 1992. 365p.

CARVALHO, N.M.; NAKAGAWA, J. Sementes: ciência, tecnologia e produção. 3.ed. Campinas: Fundação Cargill, 1988. 429p.

COONS, J.M.; KEUHL, R.O.; SIMONS, N.R. Tolerance of ten cultivars to high temperature combined with $\mathrm{NaCl}$ during germination. Journal of the American Society for Horticultural Science, Alexandria, v.115, n.6, p. 1004-1007, 1990.

GUEDES, A.C.; CANTLIFFE, D.J. Germination of lettuce seeds at high temperature after seed priming. Journal of the American Society for Horticultural Science, Alexandria, v.105, n.6, p.777781, 1980.

KAUFMANN, M.R.; ROOS, K.J. Water potential, temperature and kinetin effects on seed germination in soil and solute systems. American Journal of Botany, Baltimore, v.57, n.4, p.413-419, 1970.

LOPES, H.M. et al. Influência do potencial osmótico e da temperatura na embebição e no crescimento da radícula de sementes de cebola (Allium cepa L.). Revista Brasileira de Sementes, Brasília, v.18, n.2, p.167-172, 1996.

MAGUIRE, J.D. Speed of germination - aid in selection and evaluation for seedling emergence and vigor. Crop Science, Madison, v.2, n.2, p.176-177, 1962.

MENEZES, N.L. et al. Qualidade fisiológica de sementes de alface submetidas a diferentes temperaturas na presença e ausência de luz. Ciência Rural, Santa Maria, v.30, n.6, p.941-945, 2000.

NAKAGAWA, J. Testes de vigor baseados na avaliação de plântulas. In: VIEIRA, D.R., CARVALHO, M.N. Testes de vigor em sementes. Jaboticabal: FUNEP, p.49-86, 1994.

NASCIMENTO, W.M. ; CALIARI, M.F. Efeitos da temperatura na germinação de sementes peletizadas de alface. Horticultura Brasileira, Brasília v.7, n.1, p.67, 1989. 
NASCIMENTO, W.M.; CANTLIFFE, D.J. Prevenindo a termodormência em sementes de alface II - Mecanismos fisiológicos. Horticultura Brasileira, Brasília, v.17, n.3, p.307, 1999.

PILL, W.G.; ROJAS, J.E. Response of fluid-drilled "Grand Rapids” lettuce seeds to high temperature and low moisture. The Journal of Agricultural Science, Cambridge, v.109, n.2, p.411-414, 1987.

ROBINSON, F.E. Seed coating, precision planting, and sprinkler irrigation for optimum stand establishment. Agronomy Journal, Madison, v.68, n.4, p.694-695, 1976.

ROOS, E.E.; JACKSON, G.S. Testing coated seed: germination and moisture absorption properties. Journal of Seed Technology, Wageningen, v.1, n.2, p.86-95, 1976.

SAMPAIO, T.G.; SAMPAIO, N.V. Recobrimento de sementes. Informativo ABRATES, Londrina, v.4, n.3, p.20-52, 1994.

SILVA, J.B.C.; NAKAGAWA, J. Metodologia para avaliação de materiais cimentantes para peletização de sementes. Horticultura Brasileira, Brasília, v.16, n.1, p.31-37, 1998a.

SILVA, J.B.C.; NAKAGAWA, J. Métodos para avaliação de material de enchimento para peletização de sementes. Horticultura Brasileira, Brasília, v.16, n.1, p.44-49, 1998b.

TAMBELINI, M.; PEREZ, S.C.J.G. Efeitos de estresse hídrico simulado com peg (6000) ou manitol na germinação de sementes de barbatimão (Stryphnodendron polyphyllum Mart.). Revista Brasileira de Sementes, Brasília, v.20, n.1, p.226-232, 1998.

VALDES, V.M.; BRADFORD, K.J. Effects of seed coating and osmotic priming on the germination of lettuce seeds. Journal of the American Society for Horticultural Science, Alexandria, v.112, n.1, p.153-156, 1987.

VILLELA, F.A.; DONI FILHO, L.; SEQUEIRA, E.L. Tabela de potencial osmótico em função da concentração de polietileno glicol 6000 e da temperatura. Pesquisa Agropecuária Brasileira, Brasília, v.26, n.11/12, p.1957-1968, 1991. 